\title{
SETI for profit
}

\section{A capital idea.}

\section{Gregory Benford}

Multi-billionaire Clyde Kraft's announcement that his team had detected a SETI signal shocked the world. He claimed to have found a plainly artificial broadband signal from a star well over a thousand light years away.

His astronomers ranked behind him confirmed the discovery. They gave pulse spectra, but without labels that would let anyone find or decipher it. They omitted the celestial location or frequency. Then Kraft stepped back to the microphone and gave his terms.

"The real news is that we've found a message in the megahertz-wide signal. It's intermittently on, hard to find. But we held steady, studied the galactic plane for over a year." Kraft paused for effect, giving the world a thin smile. "Then - there it was! In less than a week my fine team deciphered it. Not hard, really. It's amazing. And ... it's a warning."

Consternation. Shouts from the press, who thought they were attending a business briefing. Kraft wouldn't reveal the message or how to find the source. $\mathrm{He}$ scowled. "I did this as an ... investment. Pay me a finder's fee, say half a billion dollars, and we'll talk." With another smile he left the dais and vanished from public view.

Around the world scientists rebuked him. "To make such a discovery and keep it secret violates the code of science," the head of the National Academy pronounced. "And to expect profit!"

Parliaments voted to condemn Kraft. "The most important discovery in history cannot be private property," declared the Pope.

Most news shows carried the story as a scandal, focusing on Kraft's known cutthroat ways of gaining advantage. He had used head-to-head methods in stochastic arbitrage trading, making him Forbes 2013 'King Competitor'. Even the Wall Street Journal went tsk-tsk. The Times in London had a headline three inches high: "What is the warning?"

Kraft wouldn't say. Appeals by politi-

cians, wise men and philosophers got no answer at all.

Worldwide, astronomers condemned Kraft - and got to work. They pored over older radio-telescope data, looking for sources 1 megahertz wide that came and went. There were several and they earned front-page coverage.

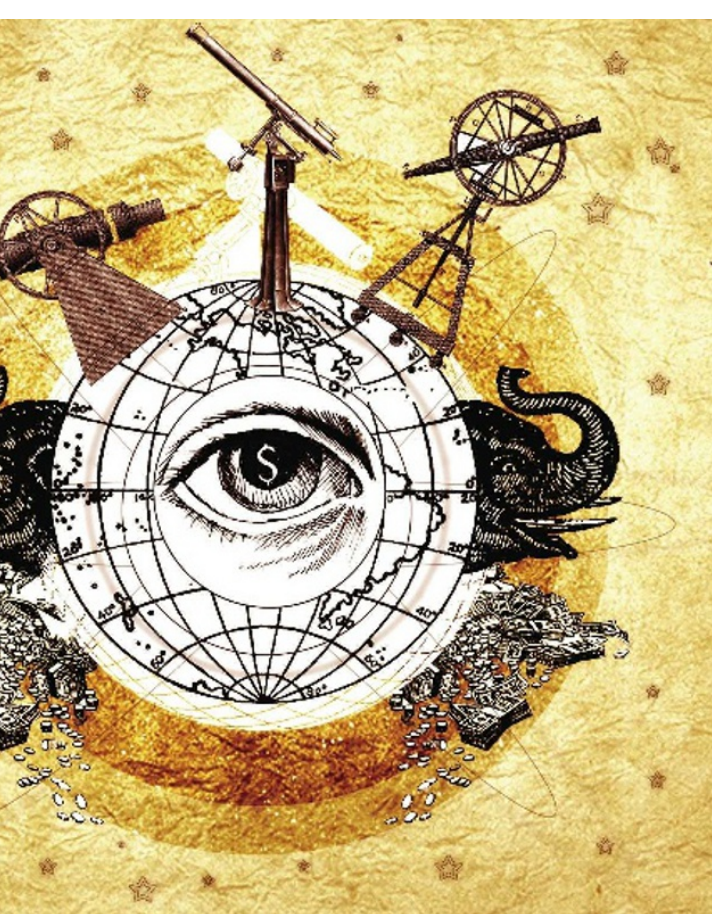

Mobs rioted outside their homes. 'Free ET!' shouted a popular sign the crowds carried in capitals around the world.

Kraft stayed in hiding. Pressure built. The Kraft astronomers also vanished, harried by incessant demands.

Months passed. The older observed signals yielded nothing. The United Nations debated whether it could or should confiscate Kraft's holdings within its reach - only to find that he had moved them into secure accounts. Nations began to negotiate how to share out the cost of meeting Kraft's price.

Kraft dodged negotiations. Rumours spread that he had become a greybearded hermit, like Howard Hughes. Reports located him in Switzerland and North Korea.

Then the Australian Parkes radio telescope picked up a quick, millisecond signal not far from the line of sight towards the galactic centre. It was 3 megahertz wide, not 1 , but it did have a signal.

Parkes released the pattern immediately. Thousands of scientists leapt to decode the message. Within days they

Dishes trained on these candidates listened constantly, to the limits of their sensitivity. Kraft would not reveal the discovery frequency so they scanned through their entire range. This was a marked change from conventional SETI, which had gathered mostly at the 'water hole' between 1 and 2 gigahertz.

Observers with telescope time donated it to the search for the mysterious source. Amateurs erected their own 3-metre radio dishes in backyards and got in on the hunt with gear they bought over the Internet.

Kraft's in-house astronomers were sound scientists who had lost out in the academic horse race. They refused even to discuss the discovery. SETI had been losing momentum since 2010, the 50th anniversary of its first search. Kraft had sought to reinvigorate the field, they said, and did so with what was to him pocket change, only $\$ 100$ million.

Scientific professional societies turned on these astronomers. Furious executives in the AAAS, the IAU and other bodies revoked the astronomers' memberships. had a coherent form, mostly details about a solar system similar to ours. It identified a race of elephant-like creatures complete with trunks, legs and two grasping hands at the shoulders. Their society was very old and might be extinct. There were hints that robots tended the message-sending beacon.

But there was no warning in the message at all.

With 30 minutes' notice, Kraft appeared at a press conference in Singapore. He admitted that there was no warning, the bandwidth was different - and in fact he had never detected a signal at all.

"I wanted to goose the world," he said. "Get 'em started. SETI needed that a lot more than it needed more money. Now we have something and it's time to get to work. I'll stand aside."

He left the room in an uproar. But that was nothing when, three years later, he won a Nobel, along with Parkes Observatory. Gregory Benford is professor of physics and astronomy at the University of California, Irvine, and a novelist. 